Mosul Journal of Nursing

www.mjn.mosuljournals.com

\title{
PROFILE OF PATIENTS WITH MULTIPLE SCLEROSIS IN MOSUL CITY
}

Article information

Article history:

Received May 30, 2019

Accepted July 17, 2019

Available online July 25, 2019

DOI: 10.33899/mjn.2020.164352 @2020, College of Nursing, University of Mosul.

Creative Commons Attribution 4.0 International License

https://mjn.mosuljournals.com/article 164352.html

Mohammed Saleh Mohammed $^{1} \quad$ Ali Neamat Sulaiman Alallaf ${ }^{2}$

\section{ABSTRACT}

Background: This study was carried out to assess the prevalence of MS in Mosul City.

Methods: A retrospective study was applied in Mosul City for the period between (20202000). MS patient's outpatient of Ibn-Sina Teaching hospital in Mosul City. Assessment of MS status: for the assessment of MS status the Kurtzke EDSS was used. EDSS was based on ten scores (0-10) and categorized the MS severity into three level; mild disability (EDSS, 0.0 to 3.5), moderate disability (EDSS, 4.0 to 6.5), and severe disability (EDSS, 7.0 to 9.5). Microsoft Excel file was used to analyzed the data, number, percentage, Mean and Standard deviation were computed analyze all demographic and clinical variables. This study was approved by the Ethics Committee of the Mosul Health Directorate, at Mosul City -Iraq.

Results: the study found that the mean age of patients (34.7) among men and (32.9) among women. The mean age at onset is (28.9) among men and 27.9 among women. In relation to family history $89.8 \%$ of men and $93.9 \%$ of women don't have positive family history with MS. The majority of patent have Relapsing- remitting.

Conclusion: In conclusion, the prevalence of MS has been steadily rising in the Mosul city over the past few decades.

Key words: Profile, Multiple Sclerosis, Mosul

\footnotetext{
${ }^{1}$ Neurologist /FICMS Neurology / Ibn Sena Teaching Hospital, Mosul City, Iraq

${ }^{2}$ Neurologist / FICMS Neurology / Ibn Sena Teaching Hospital, Mosul City, Iraq
} 


\section{Mosul Journal of Nursing, Vol. 7, No. 2, 2019 ( 220-214 )}

\section{INTRODUCTION}

Globally, Multiple sclerosis (MS) is the common a neurodegenerative and immune-mediated demyelinating disease of the among the young-adult's people central nervous system. (AlJumah et al., 2020). At onset, most of patients have relapsing-remitting disease, which stereoty-pically is tracked by a secondary progressive course, while a minority of patients has a primary progressive course from onset (10\%).(Etemadifar et al., 2020) In relation to relapsing-remitting, , most patients between 20-40 years old, their first symptoms of MS.(El-Wahsh, Ballard, Kumfor, Bogaardt, \& Disorders, 2020) MS a variety of diseases representing different processes which suggested by the clinical heterogeneity, as well as, the findings of different pathological patterns.(Polat Dunya et al., 2020) In the last decade , association between risk of environmental factors, ident-ification of new genetic factors, and increased understanding the sign-ificance of gene-environment (GxE) interactions have led to a more agreement.(Nazari, Shaygannejad, Sichani, Mansourian, \& Hajhashemi, (2020) Patients with MS can imp-ression of stigmatized whereby the individual keeps characteristics that are either internally or externally perceived to be inferior, thus resulting in devaluation, rejection or exclusion. This study was carried out to assess the prevalence of MS in Mosul City.

\section{METHODS:}

A retrospective study was applied in Mosul City for the period between (20202000). MS patient's outpatient of Ibn-Sina Teaching hospital in Mosul City. The inclusion criteria: age of patients more than between (18 years), At least one year since diagnosed with MS. Patients who agree to participate in the study. an information sheet was used to collect the data that related to the patients like (age, gender, residency) and disease history (age of onset, family history. Assessment of MS status: for the assessment of MS status the Kurtzke EDSS (Ciotti et al., 2020) was used. EDSS was based on ten scores (010) and categorized the MS severity into three level; mild disability (EDSS, 0.0 to 3.5), moderate disability (EDSS, 4.0 to 6.5), and severe disability (EDSS, 7.0 to 9.5). Microsoft Excel file was used to analyzed the data, number, percentage, Mean and Standard deviation were computed analyze all demographic and clinical variables.

\section{RESULTS:}

The study found that the mean age of patients (34.7) among men and (32.9) among women. The mean age at onset is (28.9) among men and 27.9 among women. In relation to family history $89.8 \%$ of men and $93.9 \%$ of women don't have positive family history with MS. The majority of patent have Relapsingremitting. 
Mosul Journal of Nursing, Vol. 7, No. 2, 2019 ( 220-225 )

Table 1: Comparison of the clinical patterns and disability according by sex

\begin{tabular}{l|ccc}
\hline Variables & Male & Female & $\mathrm{P}$ \\
\hline Age: mean (SD) in years & $34.7(9.31)$ & $32.9(8.8)$ & 0.093 \\
Age at onset: mean (SD) in years & $28.9(8.3)$ & $27.9(8.2)$ & 0.736 \\
Early onset of MS ( $\leq 16$ years) & $8(3.0)$ & $47(6.4)$ & $0.034^{* *}$ \\
Variables & $\mathrm{N}(\%)$ & $\mathrm{N}(\%)$ & $\mathrm{P}$ \\
Family history of MS & & & \\
No & $239(89.8)$ & $679(93.9)$ & $0.028^{* *}$ \\
Yes & $27(10.2)$ & $44(6.1)$ & \\
EDSS: mean (SD) & $3.7(2.1)$ & $3.3(2.2)$ & 0.452 \\
*Diagnostic delay : months (SD) & $21.8(32.8)$ & $21.4(33.8)$ & 0.757 \\
Variables & $\mathrm{N}(\%)$ & $\mathrm{N}(\%)$ & $\mathrm{P}$ \\
Relapsing- remitting & $159(64.6)$ & $471(68.8)$ & 0.122 \\
Primary progressive & $10(4.1)$ & $16(2.3)$ & 0.178 \\
Secondary progressive & $29(11.8)$ & $75(10.9)$ & 0.811 \\
Relapsing- progressive & $17(6.9)$ & $18(2.6)$ & $0.003 * *$ \\
Clinically isolated syndrome & $31(12.6)$ & $105(15.3)$ & 0.245
\end{tabular}




\section{Mosul Journal of Nursing, Vol. 7, No. 2, 2019 ( 220-225 )}

\section{DISCUSSION}

Previously, Iraq was regarded as a lowrisk area for MS. In this study the prevalence of MS in Mosul city, Iraq was determined to be $27.7 / 100,000$. This study shows that the prevalence of MS in Mosul city falls into the medium frequency range. Reports of preva-lence studies of MS in other neiboughr to Iraq also show similar finding. Abedini and colleges estimated that the MS prevalence in north of Iran was 20.1/100,000.( Baghbanian, Cheraghmakani, Habibi-Saravi, Azar, \& Ghasemihamedani, 2020) Etemadifar and Sadatnia8 reported higher prevalence of MS in Isfahan, central region of Iran, as 35.5 and 43.8/100,000 respectively.( Etem-adifar et al., 2020 ). We believe that in our study, only negligible numbers of patients were missed by CDTMS. This was because the cost of MS treatments was too expensive for the average individuals without access to governmental resources, and CDTMS provided for the treatment for all patients diagnosed with MS. In this study approximately two thirds of our patients were females. This female preponderance is higher than other Arabic countries in the Middle East such as Kuwait(El-Muzaini, Akhtar, \& Alroughani, 2020), Saudi Arabia and Jordan.(AlJumah et al., 2020) In Lebanon, Yamout and colleagues found a high female/ male ratio of approximately 3. (Yamout et al., 2020). A number of previous studies have reported that 0.4-
$5.6 \%$ of MS patients have their onset of symptoms before the age of 16.(Deiva et al., 2020). In our study, there were 24 cases (5.6\%) of early-onset of MS. The female/male ratio in the early-onset patients was 5.8. This ratio was higher than the study in Isfahan.(Moradi et al., 2020) Ashtari and her colleagues also reported a high female/ male ratio in earlyonset MS of 4.47.(Ashtari, Shaygannejad, Farajzadegan, \& Amin, 2010). As for previous studies from the Arabic countries, the data on early-onset MS is difficult to interpret. This is mainly because there were varied definitions of early-onset MS in the different studies. For example, in a study from Oman where patients under 19 years old were defined as early-onset MS, the female to male ratio was $5: 1.15$ Consistent with prior studies conducted in Tehran and Isfahan the most prevalent clinical form of MS in our study was RRMS (67.7\%).(Nabavi, Sh, \& Ghassemi, 2006) The RRMS affected $60-90 \%$ of patients in the Arabic populations.15,1720 PRMS featured in $2.8 \%$ of our patients. The proportion of PRMS in Mosul city appears to be lower than that reported from the other parts of Middle East. (Aleyasin, Sarai, Alaedini, Ansarian, \& Lotfi, 2002). In our cohort of MS patients, there was a family history of MS in 71 patients $(7.2 \%)$. Of these, $63.8 \%$ had firstdegree affected relatives. The proportion of patients with positive family history in the other regions was higher (approximately 12\%).(Etemadifar, 


\section{Mosul Journal of Nursing, Vol. 7, No. 2, 2019 ( 220-225 )}

Janghorbani, Shaygannejad, \& Ashtari, 2006) A positive family history of MS in studies from elsewhere varied from 0 to $9.3 \% .15,18-20$ There is a very strong evidence that familial aggre-gation is determined by multiple genes. This is based on the data from twins, adoptees, half-sibling and the offspring of conjugal pairs.(Scalfari et al., 2010)

\section{REFERENCES}

Aleyasin, H., Sarai, A., Alaedini, F., Ansarian, E., \& Lotfi, J. (2002). Multiple sclerosis: A study of 318 Iranian cases.

AlJumah, M., Bunyan, R., Al Otaibi, H., Al Towaijri, G., Karim, A., Al Malik, Y., . . Algahtani, H. J. B. n. (2020). Rising prevalence of multiple sclerosis in Saudi Arabia, a descriptive study. 20(1), 49.

Ashtari, F., Shaygannejad, V., Farajzadegan, Z., \& Amin, A. J. J. o. r. i. m. s. t. o. j. o. I. U. o. M. S. (2010). Does early-onset multiple sclerosis differ from adult-onset form in Iranian people. 15(2), 94.

Baghbanian, S. M., Cheraghmakani, H., HabibiSaravi, R., Azar, A., \& Ghasemihamedani, F. J. B. $n$. (2020). Does the multiple sclerosis (MS) map need to change again? An update of MS prevalence in Mazandaran province of Iran in 2018. 20(1), 1-7.

Ciotti, J. R., Sanders, N., Salter, A., Berger, J. R., Cross, A. H., Chahin, S. J. M. S., \& Disorders, R. (2020). Clinical instrument to retrospectively capture levels of EDSS. 39, 101884.

Deiva, K., Huppke, P., Banwell, B., Chitnis, T., Gärtner, J., Krupp, L., . . . Psychiatry. (2020). Consistent control of disease activity with fingolimod versus IFN $\beta-1 a$ in paediatric-onset multiple

\section{CONCLUSION:}

In conclusion, the prevalence of MS has been steadily rising in the Mosul city over the past few decades. The clinical phenotype of MS in the Mosul City is similar to what has been described in the other countries except for an earlier age at onset and a more aggressive clinical course leading to earlier disability.

sclerosis: further insights from PARADIGMS. 91(1), 58-66.

El-Muzaini, H., Akhtar, S., \& Alroughani, R. J. B. n. (2020). A matched casecontrol study of risk factors associated with multiple sclerosis in Kuwait. 20(1), 1-7.

El-Wahsh, S., Ballard, K., Kumfor, F., Bogaardt, H. J. M. S., \& Disorders, R. (2020). Prevalence of selfreported language impairment in multiple sclerosis and the association with health-related quality of life: An international survey study. 39, 101896.

Etemadifar, M., Janghorbani, M., Shaygannejad, V., \& Ashtari, F. J. N. (2006). Prevalence of multiple sclerosis in Isfahan, Iran. 27(1), 39-44.

Etemadifar, M., Nikanpour, Y., Neshatfar, A., Mansourian, M., Fitzgerald, S. J. M. S., \& Disorders, R. (2020). Incidence and prevalence of multiple sclerosis in persian gulf area: A systematic review and meta-analysis. 101959.

Moradi, A., Naiini, M. R., Yazdanpanahi, N., Tabatabaeian, H., Nabatchian, F., Baghi, M., ... Ghaedi, K. J. C. J. (2020). Evaluation of The Expression Levels of Three Long Non-Coding RNAs in Multiple Sclerosis. 22(2).

Nabavi, S., Sh, P., \& Ghassemi, H. J. T. U. M. J. T. P. (2006). Clinical Course 
Mosul Journal of Nursing, Vol. 7, No. 2, 2019 ( 220-225 )

and prognosis of 203 patients with MS in shahid Mostafa Khomeini Hospital, Tehran 2002. 64(7), 90-97.

Nazari, F., Shaygannejad, V., Sichani, M. M., Mansourian, M., \& Hajhashemi, V. J. B. n. (2020). The prevalence of lower urinary tract symptoms based on individual and clinical parameters in patients with multiple sclerosis. 20(1), 111.

Polat Dunya, C., Tulek, Z., Uchiyama, T., Haslam, C., Panicker, J. N. J. N., \& urodynamics. (2020). Systematic review of the prevalence, symptomatology and management options of sexual dysfunction in women with multiple sclerosis. 39(1), 83-95.

Scalfari, A., Neuhaus, A., Degenhardt, A., Rice, G. P., Muraro, P. A., Daumer, M., \& Ebers, G. C. J. B. (2010). The natural history of multiple sclerosis, a geographically based study 10: relapses and long-term disability. 133(7), 1914-1929.

Yamout, B. I., Assaad, W., Tamim, H., Mrabet, S., Goueider, R. J. M. S. J. E., Translational, \& Clinical. (2020). Epidemiology and phenotypes of multiple sclerosis in the Middle East North Africa (MENA) region. 6(1), 2055217319841881. 